\title{
LA AMAZONÍA Y EL PETÉN: ¿DOS LUGARES IMPROBABLES PARA EL DESARROLLO DE LAS CIVILIZACIONES?
}

\section{AMAZON AND PETÉN: TWO REGIONS UNSUITABLE FOR THE DEVELOPMENT OF CIVILIZATION?}

\author{
Juan Carlos Solórzano Fonseca*
}

\begin{abstract}
Resumen: Durante casi todo el siglo XX los investigadores dieron por sentado que la región del Amazonas en Brasil, el Petén en Guatemala, Belice y sur de Yucatán eran territorios cuyo tipo de suelos, vegetación y clima no eran aptos para sustentar una agricultura productiva, sostenible a largo plazo y capaz de sustentar grandes concentraciones de población, ni sociedades complejas en la época precolombina. No fue sino hasta finales de la centuria pasada que gracias a las investigaciones arqueológicas y etnohistóricas de las últimas décadas se modificó tal visión. La información reciente viene a probar que tanto en la Amazonía como el Petén sus pobladores fueron capaces de implementar técnicas de producción agrícola adaptadas a la ecología de la región, capaces de generar excedentes suficientes para un gran crecimiento poblacional. Esto posibilitaría la aparición de sociedades no solo de gran densidad demográfica sino también de gran complejidad social.
\end{abstract}

Palabras claves: arqueología; Amazonas; Petén; agricultura; sostenibilidad ambiental de largo plazo; historia.

Abstract: For most of the Twentieth century archeologists and ethnologists agreed to think that regions such as the Amazon in Brazil, Peten forest in

Fecha de recepción: 01/06/2018-Fecha de aceptación: 01/07/2018

* Costarricense. Doctor en Historia por la École des Hautes Études en Sciencies Sociales (EHESS), Francia. Es académico de número de la Academia de Geografía e Historia de Costa Rica y correspondiente en la Academia de Historia y Geografía de Guatemala. Correo electrónico: jcsolorzanof@gmail.com 
Guatemala, Belice and southern Yucatan were areas where agricultural systems able to support large population centers with complex societies were not possible at pre-Columbian times. Their type of soils, vegetation and climate made this step in civilization almost unattainable. However, new findings and studies at the end of last century challenged this idea. New data and close examinations of old chronicles from Sixteenth and Seventeenth centuries probe that autochthonous populations inhabiting the Amazon as well as Peten forest managed to develop sophisticated and productive farming systems. These techniques could not only feed large populations but made also possible the rise of complex societies.

Keywords: Archaeology; Amazon; Peten; Agriculture, Long-Term Environmental Sustainability; History.

"Hemos tenido esta presunción occidental de que las civilizaciones complejas no pueden florecer en los trópicos, que los trópicos son donde mueren las civilizaciones". Marcello Canuto, Universidad de Tulane

\section{Introducción}

La agricultura en zonas de selva tropical constituye una actividad bastante azarosa: a pesar de las lluvias abundantes y el clima favorable, los suelos en estas regiones son de poco espesor y la mayor parte de la biomasa se ubica en los doseles formados por las copas de los árboles. Como consecuencia, la mayoría de las formas utilizadas para clarear la selva y proceder a su siembra provocan la rápida desaparición de los nutrientes en sus suelos, los que expuestos al intenso sol tropical dan lugar a que estos terminen convertidos en superficies de dura roca laterítica. La delicada ecología del ambiente de selva tropical y en particular la frágil naturaleza de sus suelos llevó a que los investigadores durante largos años pensaran que tales suelos eran incapaces de sustentar civilizaciones o poblaciones numerosas.

En la región de la Amazonía la antropóloga estadounidense Betty Meggers en un estudio trascendental, Man and Culture in a Counterfeit Paradise, publicado en 1971, argumentó que la lujuriosa vegetación de la selva amazónica habría impuesto significativas limitaciones para la obtención de recursos por parte de los humanos, lo que impidió que se produjese un incremento poblacional, así como su evolución hacia una mayor complejidad social que la de tribus o diminutos cacicazgos. ${ }^{1}$

En el extenso territorio del Petén, en las tierras bajas del este guatemalteco, por el contrario, la abundancia de restos de ruinas de templos, palacios,

1 Betty J. Meggers, Amazonia: Man and Culture in a Counterfeit Paradise, edición revisada (EE. UU.: Smithsonian Institute, 1996). 
pirámides y estelas de piedra con enigmáticos jeroglíficos dejaba a las claras que, a diferencia de la Amazonía y a pesar de la semejanza del ambiente geográfico de la selva tropical lluviosa, allí había tenido lugar un fenómeno civilizatorio. Ello no fue óbice para que se planteara que la selva tropical, tal como en la Amazonía, debería haber impuesto serias limitaciones para la producción de recursos alimenticios suficientes para que surgieran sociedades muy -pobladas. Fue precisamente la misma antropóloga Betty Meggers quien adujo que allí no podría surgir una civilización, o bien, que esta rápidamente se vería conducida al colapso, puesto que la selva tropical solo permitiría el desarrollo de una agricultura de tala y quema, incapaz de extenderse o sustentarse largo tiempo sin que provocara el agotamiento de los suelos y por tanto la imposibilidad de sustentar una agricultura permanente, base imprescindible para el sustento de una gran población. ${ }^{2} \mathrm{La}$ explicación de la antropóloga Meggers constituyó el principal argumento para afirmar que los centros ceremoniales mayas con sus impresionantes edificaciones habían sido lugares poco habitados, ocupados solo por sacerdotes encargados de realizar ceremonias cada cierto tiempo, donde convergían solo periódicamente agricultores procedentes de comunidades aldeanas poco pobladas, dispersas y situadas en contornos relativamente alejados de dichos centros.

La Amazonía fue concebida como una región que estuvo poblada solo por pequeños caseríos aislados unos de otros, que agrupaban pocas familias patriarcales, por lo general rodeadas de paliçadas -empalizadas- defensivas. Los grupos humanos que disponían de cultivos no podían permanecer mucho tiempo en un solo lugar: al agotarse los suelos debían desplazarse hacia otros sectores en los bosques, donde nuevamente procedían a clarear un terreno para sus nuevas siembras.

En el caso de los mayas de las tierras bajas, la idea que predominó fue la de una civilización conformada por una sociedad de agricultores aldeanos que vivían dispersos en comunidades alejadas de los imponentes centros ceremoniales. Estos eran concebidos como lugares poco poblados, donde un pequeño grupo de sacerdotes dedicados a filosofar, a observar el cielo y a pensar en el fenómeno del tiempo congregaba con cierta frecuencia a los agricultores de las comunidades vecinas, quienes participaban así en las ceremonias religiosas que estos realizaban.

Se elaboró la hipótesis de que los agricultores mayas de la antigüedad subsistían mediante la práctica de una agricultura de roza y quema -o de tala y quema- semejante a la de los agricultores de la Amazonía: por medio de la roza y quema de parcelas en la selva, se procedía a la siembra de maíz, frijoles y calabazas. Pero como los suelos tropicales se consideraron extremadamente frágiles, se planteó que en muy pocos años quedaban agotados, viéndose los

2 Betty J. Meggers, "Environmental Limitation on the Development of Culture", American Anthropologist (EE. UU.) 56 (1954): 801-824, URL: https://www.jstor.org/stable/663814. 
agricultores obligados a abrir nuevos claros en otro sector de la selva y esperar largos años antes de que la selva volviese a reconstituirse y los suelos recuperaran su fertilidad. Tal sistema agrícola habría obligado a que la población fuese escasa y hubiese tenido que vivir dispersa en torno a los centros ceremoniales, donde solo convergían para la celebración de ceremonias, convocados por la élite sacerdotal.

La visión de una Amazonía poco poblada y con habitantes dispersos en aldeas de pocas dimensiones y separadas entre sí unas de otras, así como la idea de que los mayas del Petén vivían también de la misma manera y que las masivas acrópolis que concentraban templos y otros edificios públicos eran muy escasamente poblados, predominó durante largo tiempo.

Ambas sociedades, tanto la amazónica como la maya, según la visión predominante durante largas décadas, habrían tenido entonces una organización socioeconómica bastante similar: cultivadores habitantes de pequeñas aldeas, obligados a desplazarse periódicamente, a clarear nuevos terrenos en la selva y abandonar los anteriores sitios de ocupación agrícola, con el fin de que estos recuperasen los nutrientes perdidos, tras varios años de siembra continua.

\section{La región amazónica}

Francisco de Orellana comandó la primera expedición europea que recorrió todo el trayecto del río Amazonas en los años 1541-1542. Como capellán de la expedición se unió el misionero dominico Gaspar de Carvajal, quien escribió una detallada crónica del recorrido realizado por los expedicionarios: Relación del nuevo descubrimiento del famoso río Grande que descubrió por muy gran ventura el capitán Francisco de Orellana. Esta se reconoce en la actualidad como una rica fuente de información etnológica, pues describe la disposición y tamaño de los poblados, así como la ocupación continua de habitantes a lo largo de las barrancas del río, la existencia de caminos amplios que comunican el río Amazonas con la tierra firme, tácticas de guerra, rituales, costumbres y utensilios de los nativos y deja patente lo poblado que se encontraba el territorio que circundaba el río. Partes de esta crónica aparecieron en la Historia general y natural de las Indias, que escribió Gonzalo Fernández de Oviedo en 1542. Sin embargo, no fue sino hasta en 1895 que el erudito chileno José Toribio Medina la publicó de manera completa. Y, aunque fue de nuevo publicada por H. C. Heaton en 1934, posteriormente cayó en el olvido.

El Diario o Relación de Orellana obtuvo hace una década una nueva preeminencia debido a las investigaciones arqueológicas que llevó a cabo la investigadora estadounidense Anna Roosevelt, cuyos resultados fueron publicitados por Charles C. Mann en el año 2005, en su libro de divulgación histórica 
publicado en español al año siguiente, 1491: Una nueva historia de las Américas antes de Colón. ${ }^{3}$

Previamente, la arqueóloga y antropóloga italo-mexicana Laurette Sejourné había señalado, basándose en la información suministrada por Carvajal, como las orillas del río estaban ocupadas por sociedades fuertemente estructuradas y si bien, afirma esta autora, los establecimientos observados por Carvajal parecen ser dependencias de ciudades del interior -pesquerías, centros de comercio, casas de fincas-, no por ello dejan de presentar caracteres de vida urbana: densidad de población; organizaciones defensivas que muchas veces impiden que los españoles se acerquen a ellas; amplios caminos y numerosos; fortificaciones; plazas espaciosas, edificios públicos, en los cuales observa Carvajal "había muchas vestiduras de plumas de diversos colores, con las cuales se vestían los indios para celebrar sus fiestas..." Los pueblos se sucedían con tal frecuencia que el Amazonas aparecía a los ojos de los europeos como un río metropolitano. ${ }^{4}$

Entre la información citada por Carvajal citamos los siguientes pasajes, evidencia de lo poblado de la región:

“... y una mañana, a la hora de las ocho, vimos sobre un alto una hermosa población que al parecer debía ser cabeza de un gran señorío... no discrepaba un pueblo de otro, distancia de media legua y menos en toda aquella banda del río de la mano diestra, que es a la banda del sur. Y aún más digo, que la tierra adentro, a dos leguas y más o menos parecían muy grandes cibdades que estaban blanqueando, y demás de esto es la tierra tan buena y tan fértil y tan al natural como la nuestra España...".5

Esta descripción corresponde a una "provincia" que Carvajal llama de San Juan, por haberla visto el día de San Juan, la cual dice se extiende por la costa del río por más de 150 leguas "plena de poblados ubicados muy próximos unos de otros". Más adelante en fecha 25 de junio de 1541, Carvajal dice haberse adentrado en unas islas las cuales pensaron se encontraban deshabitadas, lo cual rectifica:

“... pero después que nos hallamos en medio de ellas fueron tantas las poblaciones que en las dichas islas parecían y vimos, de que nos pesó, y como nos vieron salieron a nosotros al río sobre doscientas piraguas, que son que cada una trae 20 y 30 indios y algunas traen a $40-$ de estas hobo muchas-...". ${ }^{6}$

3 Charles C. Mann, 1491: Una nueva historia de las Américas antes de Colón (Madrid, España: Editorial Santillana, 2006).

4 Laurette Sejourné, América Latina. Tomo I. Antiguas culturas precolombinas (Madrid, España: Siglo XXI Editores, 1994, 13ª edición), 118-119.

5 Darcy Ribeiro y Carlos de Araujo Moreira Neto (compiladores), La fundación de Brasil: testimonios (1500-1700) (Caracas, Venezuela: Biblioteca Ayacucho, 1992), 463. Gaspar de Carvajal, Relación del nuevo descubrimiento del famoso Río Grande de las Amazonas, Jorge Hernández Millares (ed.) (México, D.F.: Fondo de Cultura Económica, 1955).

6 Ibid. 
Francisco Vázquez, quien escribió la crónica de la expedición que realizó Pedro de Ursúa veinte años más tarde que la que llevó a cabo Orellana, también brinda información de la región amazónica, la cual aparece muy poblada en las márgenes del Amazonas y las planicies ribereñas de los principales ríos. ${ }^{7}$

La información de ambos cronistas, quienes indicaban la existencia de grandes ciudades, bien desarrolladas carreteras, montículos monumentales, pueblos fortificados, así como una densa población, fue desechada al afirmarse que se trataba de fantasías y exageraciones de los narradores, especialmente de Carvajal quien brinda más datos.

Ha sido solo a partir de las últimas décadas que un número de investigadores han evidenciado las estrechas interacciones entre los humanos y el ambiente en la cuenca amazónica. Han demostrado el manejo antropogénico de un paisaje considerado durante muchos años como "prístino". Gracias a estos trabajos se ha podido determinar que los humanos han intervenido el paisaje de la Amazonía desde aproximadamente 11.000 años antes de nuestra era. Se ha puesto atención al manejo agrícola de los bosques, así como a la extensa difusión de la llamada tierra negra antropogénica tanto en los terrenos inundables de los ríos como en la llamada "tierra firme" o alta no inundable. Y, más recientemente, los numerosos cortes en los cuellos de los meandros de los ríos, realizados con la intención de acortar la comunicación fluvial para el transporte de numerosos productos a lo largo de toda la región amazónica. Todos estos trabajos han confirmado la gran actividad humana existente en la cuenca amazónica antes del arribo de los europeos y de la modelación de su paisaje selvático y de sus suelos. ${ }^{8}$

Los sistemas fluviales, cruciales para los grupos indígenas como medio de subsistencia, fueron las rutas de intercomunicación de toda el área. Se trata de regiones con sus características propias. En ellas abundaban recursos para la subsistencia humana: grandes planicies inundables, extensas costas y estuarios y tierras elevadas calizas o volcánicas. Sin embargo, hace medio siglo la perspectiva que los investigadores tenían sobre la región amazónica era completamente diferente.

Fue en la década de 1950, cuando la arqueóloga estadounidense Betty Meggers elaboró la hipótesis sobre los suelos ácidos de la Amazonía, los cuales, argumentó, eran incapaces de mantener el nivel de agricultura necesario para sostener una población de la densidad señalada por Carvajal o siquiera para construir las ciudades, montículos y redes de caminos señalados por el cronista. Por tanto, se consideró a Gaspar de Carvajal como fantasioso en el mejor de los casos.

El enfoque de Meggers vino a reforzar la idea, ya aceptada por los estudiosos de los informes de los frailes misioneros -quienes durante el siglo XVIII

7 Francisco Vázquez, El Dorado. Crónica de la expedición de Pedro de Ursúa y Lope de Aguirre, Javier Ortiz de la Tabla (ed.) (Madrid, España: Alianza Editorial, 1987).

8 Hugh Raffles y Antoinette M. G. A. Winkler Prins, "Further Reflections on Amazonian Environmental History: Transformations of Rivers and Streams", Latin American Research Review (EE. UU.) 38, n. 3 (2003): 165-187, URL: https://www.jstor.org/stable/1555454. 
realizaron tareas de evangelización en la región amazónica-, de que los habitantes de la Amazonía se caracterizaban por agruparse en poblaciones pequeñas, dispersas en la selva y con estructuras sociales muy básicas. Se trataba, pues, de un modo de vida sustentado en la caza, la recolección y la pesca. Y aunque algunos grupos disponían de cultivos, no podían permanecer mucho tiempo en un solo lugar. Al agotarse los suelos debían desplazarse hacia otros sectores en los bosques donde nuevamente procedían a clarear un terreno para sus nuevas siembras.

Solo a raíz de las investigaciones arqueológicas pioneras de Anna Roosevelt y de otros que han seguido sus pasos, en los comienzos de la actual centuria se ha comenzado a aceptar que lo escrito por Carvajal no era fantasía y más bien se considera su Relación como la crónica contemporánea de la cultura Amazónica prehispánica más valiosa, única escrita antes de que esta desapareciera y sus obras materiales fueran cubiertas por la selva. El libro de Roosevelt, Moundbuilders of the Amazon: Geophysical Archaeology on Marajo Island Brazil, desafió la teoría de Meggers de que las características de esta región no permitieran el sustento de una población densa y organizaciones sociopolíticas complejas. Para Roosevelt las sociedades que surgieron en el Amazonas lograron "uno de los más sobresalientes logros culturales, con alta concentración de población, agricultura intensiva de subsistencia, así como construcciones públicas de gran envergadura". 9

En la actualidad, investigadores brasileños del Proyecto Central Amazónico investigan las culturas precolombinas que existieron en la región central amazónica, desde el 2300 al 500 años antes del presente. Los fragmentos de cerámica, así como la existencia de un suelo negro llamado Terra Preta, han ayudado a reelaborar el conocimiento de la vida y la cultura para millones de seres humanos que vivieron en el Amazonas antes del arribo de los europeos. Así, Eduardo Goés Neves, un renombrado arqueólogo brasileño en compañía de investigadores de los Estados Unidos, han encontrado vastas extensiones de tierra negra o "preta", tierra fértil conformada mediante la mezcla de carbón, desechos y otra materia orgánica con la tierra. En 15 años de trabajo, han también encontrado vastos espacios, verdaderos vergeles o huertos con árboles frutales semidomesticados que parecen bosques modelados por la intervención humana. ${ }^{10}$

Por su parte, Michael Heckenberger de la Universidad de Florida ha encontrado fosos, calzadas, canales, así como una red de construcciones pertenecientes a una estratificada civilización que habría surgido tan pronto como en el año 800 de nuestra era. En Bolivia varios arqueólogos de diversas nacionalidades se

9 Anna Curtenius Roosevelt, Moundbuilders of the Amazon: Geophysical Archaeology on Marajo Island, Brazil (San Diego, EE. UU.: Academic Press, 1991).

10 Eduardo Goés Neves, James B. Petersen, Robert N. Bartone y Michael J. Heckenberger, "The Timing of Terra Preta Formation in the Central Amazon: Archaeological Data from Three Sites", en: Amazonian Dark Earths: Explorations in Space and Time, Bruno Glaser y William I. Woods (eds.) (Berlin, Heidelberg, Alemania: Springer, 2004). 
encuentran investigando cómo los pobladores de una sociedad que surgió siglos antes de Cristo removieron toneladas de suelo y desviaron ríos como parte de grandes proyectos agrícolas y de piscicultura. ${ }^{11}$

Muchas de estas investigaciones arqueológicas se han inspirado en el trabajo pionero llevado a cabo por Anna C. Roosevelt durante los años de la década de 1980 en la isla de Marajó, una isla de alrededor de $50.000 \mathrm{~km}^{2}$ en la desembocadura del río Amazonas. En sus investigaciones Roosevelt descubrió fundaciones de casas, elaborada cerámica y evidencia de una avanzada agricultura capaz de haber permitido el surgimiento de una sociedad de más de 100.000 habitantes.

Inicialmente, Roosevelt publicó las conclusiones de su trabajo en el año 1991. Estos resultados ayudaron a redirigir el pensamiento científico sobre la Amazonía, atrayendo a toda una pléyade de jóvenes arqueólogos que siguieron sus propuestas de investigación en otras partes de la inmensa región amazónica.

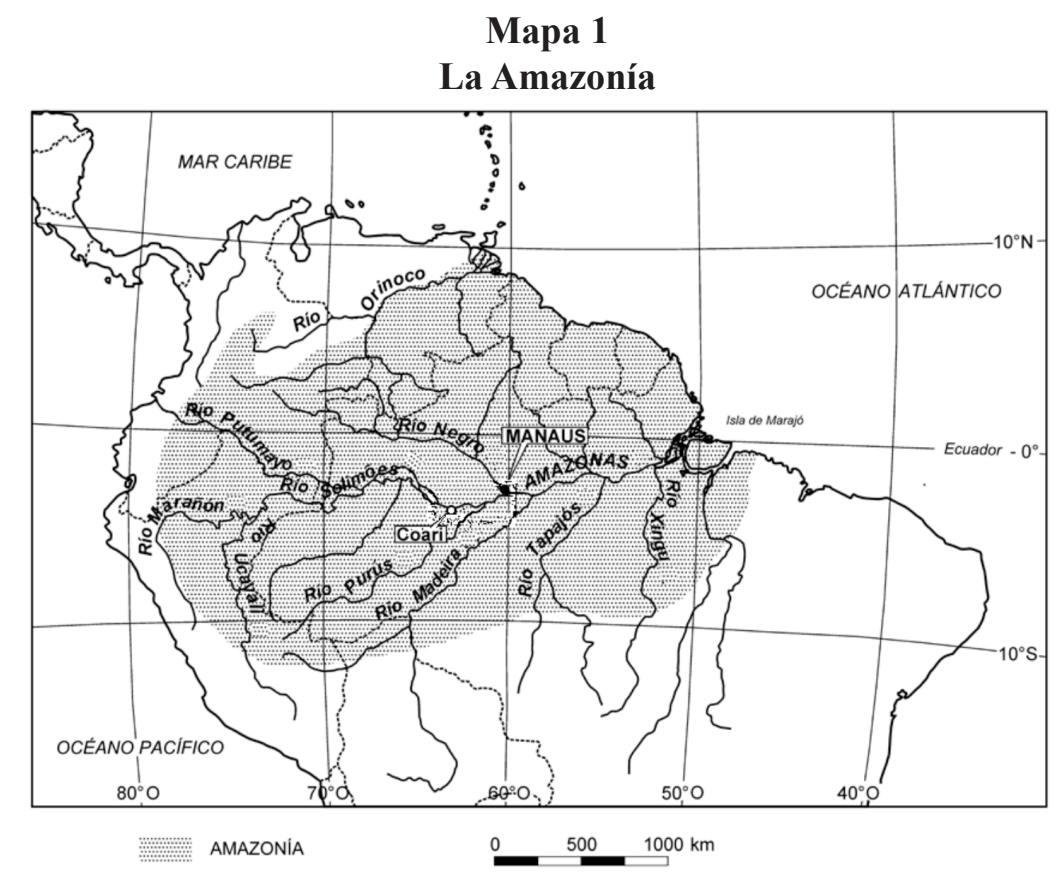

Fuente: con modificaciones menores, tomado de Eduardo Góes Neves, "El Formativo que nunca terminó: la larga historia de estabilidad en las ocupaciones humanas de la Amazonía Central", Boletín de Arqueología, Pontificia Universidad Católica del Perú (PUCP) 11 (2007): 119, bajo licencia de Creative Commons Reconocimiento 4.0 Internacional. (https://creativecommons.org/licenses/by/4.0/deed.es); URL: http://revistas.pucp.edu.pe/ index.php/boletindearqueologia/article/view/1824.

11 Michael Heckenberger, The Ecology of Power: Culture, Place, and Personhood in the Southern Amazon, A.D. 1000-2000 (Oxford, Inglaterra: Routledge, 2005). 
Gracias a las investigaciones realizadas, la imagen que en la actualidad tenemos de la Amazonía de hace mil años constituye un mundo no solamente muy diferente a como es hoy, sino también a como lo hemos imaginado. No habría grandes áreas desbrozadas y ocupadas por pastizales o cultivos. Existía una selva, pero que a trechos estaría ocupada por claros de bosque habitados por humanos: grandes aldeas o incluso ciudades rodeadas de áreas de cultivos, vinculadas entre sí por medio de anchos y largos caminos. En algunas localidades se encontraban centros ceremoniales delimitados por alineamientos de piedras colocados en forma de círculos. Montículos elevados servirían de morada y de lugar para el desarrollo de rituales. ${ }^{12}$

Las investigaciones actuales plantean entonces que, desde alrededor de los inicios de nuestra era en adelante, se produjo un crecimiento notable y generalizado de la población, la aglutinación de sitios y transformaciones evidentes en el paisaje antrópico. Estas corresponden, en el registro arqueológico, a la aparición súbita de conjuntos de mayores dimensiones, con profundos depósitos estratificados de cerámica asociados con tierras antrópicas de color oscuro, campos de cultivo y caminos elevados, grandes aldeas rodeadas por fosos y conectadas por redes de caminos, montículos artificiales residenciales y mortuorios asociados con cerámica elaborada, sistemas de asentamientos casi urbanos, estatuaria de piedra pulida, redes de comercio de largo alcance y la construcción de estructuras megalíticas circulares. ${ }^{13}$

Estudios arqueológicos realizados en la Amazonía boliviana evidencian todo un laberinto de diques, presas y canales que se encontraban distribuidos por millares de kilómetros cuadrados. ${ }^{14}$ Entonces, a diferencia de la imagen corriente de que la Amazonía fue siempre una selva indómita, un paraíso prístino, donde la huella del hombre apenas si dejó traza, pues sus pobladores escasos vivían de la recolección y la caza o a lo más de la agricultura de roza y quema, desplazándose constantemente en medio de la inmensidad verde, el aspecto que nos develan las investigaciones más recientes es completamente diferente: la Amazonía se encontraba ocupada por centenares de sociedades indígenas de muy diverso tipo: algunas eran sociedades jerarquizadas, lideradas por jefes supremos, capaces de dirigir ejércitos de guerreros. Algunas otras no alcanzaban ese nivel de gran jerarquización y desarrollo y ciertamente la componían grupos pequeños de cazadores-recolectores nómadas, quienes empleaban cerbatanas para la caza de

12 Charles C. Mann, 1491: New Revelations of the Americas Before Columbus (New York, EE. UU.: Vintage Books, 2006), 280-311.

13 Eduardo Góes Neves, "El Formativo que nunca terminó: la larga historia de estabilidad en las ocupaciones humanas de la Amazonía central", Boletín de Arqueología PUCP (Perú) 11 (2007): 117, URL: http://revistas.pucp.edu.pe/index.php/boletindearqueologia/article/view/1824.

14 Umberto Lombardo, Elisa Canal-Beeby, Seraina Fehr y Heinz Veit, "Raised Fields in the Bolivian Amazonia: A Prehistoric Green Revolution or a Flood Risk Mitigation Strategy?", Journal of Archaeological Science, 38, n. 3 (marzo, 2011): 502-512, DOI: https://doi.org/10.1016/j.jas.2010.09.022. 
monos y otros animales. Es decir, en esa inmensa extensión territorial había infinidad de sociedades con diversos grados de complejidad social y también lingüística.

Característica de la región amazónica es la carencia de formaciones rocosas, piedra, por lo que la materia prima para la construcción en la floresta amazónica siempre fue la tierra y la madera. Los sitios arqueológicos se caracterizan por ser montículos o fosas, los cuales fueron cubiertos por la selva cuando se inició la colonización europea que trajo las enfermedades, la desorganización social, la esclavitud, la guerra y la muerte de gran número de la población autóctona.

Se calcula que la población que se concentraba a lo largo de la enorme extensión recorrida por el río Amazonas podía alcanzar los 5 millones de habitantes. Esta población desapareció de manera súbita, dejando incontables sitios arqueológicos que estuvieron ocupados hasta los propios inicios del período colonial en el siglo XVI. Es por eso que se plantea que, mientras en Europa, los cristianos de España luchaban por retomar las tierras que controlaban los árabes, en la Amazonía, sus poblaciones alcanzaron un gran florecimiento cultural. De manera que, en la isla Marajó, o en otras localidades brasileñas como Manaus o Santarém, sus habitantes produjeron cerámicas con patrones gráficos de gran sofisticación. ${ }^{15}$

La civilización de Marajó protagonizó cerca de mil años de evolución cultural hasta su desaparición justo al momento de la llegada de los europeos. Su apogeo se sitúa en torno al año 1000, cuando esculturas de piedra eran esculpidas en la desembocadura del río Trombetas, próxima a la actual Oriximiná, donde se localizaban también centros de producción de muiraquitas, pequeñas esculturas de piedra pulida en forma de animales o seres humanos. ${ }^{16}$ En el alto Xingu, grandes aldeas circulares fueron construidas con conceptos de urbanismo sofisticado, al tiempo que en Acre florecían aldeas características por sus estructuras geométricas, concebidas actualmente como geoglifos. ${ }^{17}$

Las investigaciones arqueológicas constituyen sin duda el camino para el estudio de diferentes historias de la ocupación humana en los distintos y variados territorios de Amazonas. Por ejemplo, la castanha o nuez de Brasil es un árbol gigante que sobrepasa la altura media de las copas de la floresta brasileña. Este árbol tarda décadas en crecer y comenzar a fructificar. Algunos tienen centenares de años. Se sabe en la actualidad que la dispersión de estos árboles ocurrió

15 Henri Feriz, "The Ceramics of Tefé-Amaná. A contribution to the archaeology of the Amazon", Ethnos. Journal of Anthropology, 28, n. 2-4 (julio, 2010): 147-176, DOI: https://doi.org/10.1080/00141844.1963. 9980936.

16 Marcondes Lima da Costa, Anna Cristina Resque Lopes da Silva y Rômulo Simões Angélica, "Muyrakytã ou muiraquitã, um talismã arqueológico em jade procedente da Amazônia: uma revisão histórica e considerações antropogeológicas", Acta Amazónica (Brasil) 32, n. 3 (2002): 467-490, DOI: http://dx.doi. org/10.1590/1809-43922002323490.

17 Jennifer Watling, José Iriarte, Francis E. Mayle, Denise Schaan, Luiz C. R. Pessenda, Neil J. Loader, F. Alayne Street-Perrott, Ruth E. Dickau, Antonia Damasceno y Alceu Ranzi, "Impact of Pre-Columbian 'Geoglyph' Builders on Amazonian Forests”, Proceedings of the National Academy of Sciences (PNAS) (EE. UU.) 114, n. 8 (febrero, 2017): 1868-1873, DOI: https://doi.org/10.1073/pnas.1614359114. 
a partir de un centro original en el este de Pará. También sabemos que solo los cutís y los humanos son capaces de quebrar la cáscara de esta nuez y dispersarla. Por tanto, es una certeza que la dispersión de esta nuez de Brasil solo se pudo realizar por intermedio de los humanos. Por otra parte, la muy escasa variabilidad genética entre las castanheiras localizadas en distintos puntos de la Amazonía, casi como si fuesen clonadas, sugiere un proceso de dispersión que comenzó dos mil años atrás, en sincronía con el proceso de florecimiento cultural de los sitios arqueológicos localizados. De lo cual podemos concluir que la dispersión de las castanhais no puede ser solo un producto de la naturaleza, sino resultado concreto de la antigua presencia humana en el Amazonas. ${ }^{18}$

Entre los mejores marcadores de las actividades humanas antiguas conocidas, lo constituyen las llamadas "terras pretas de índio", verdaderos indicadores arqueológicos del surgimiento de los modos de vida sedentarios en el pasado amazónico. Son estos suelos muy fértiles, de coloración oscura en los cuales se encuentran millares de fragmentos cerámicos. Estos suelos de terra preta pueden alcanzar más de dos metros de profundidad. Debido a su altísima fertilidad estas tierras son buscadas por los agricultores de hoy día, quienes reconocen sus propiedades y saben que en ellas existen mejores condiciones de cultivo. Durante muchos años se las consideraba "naturales" por los científicos. Hace unas dos décadas, gracias a las investigaciones pioneras de Dirse Kern del Museu Paraense Emilio Goeldi, se logró determinar que sus componentes químicos resultan de antiguas actividades humanas. Por ejemplo, los fosfatos provienen de los huesos de animales allí depositados y de los fragmentos de carbón quemado a baja temperatura. Estas "tierras negras" o pretas tienen otras propiedades: se trata de suelos estables, capaces de mantener por décadas o siglos sus condiciones de alta fertilidad. Esta condición constituye una anomalía en los contextos ecuatoriales, donde debido a la acción de las lluvias y de la evaporación, los suelos no consiguen preservar por mucho tiempo sus nutrientes. ${ }^{19}$

Se ha calificado al sistema empleado en el pasado por los indígenas brasileños para elaborar la tierra negra con el nombre de slash and char en contraposición al sistema de slash and burn que destruye la fertilidad del suelo. En lugar de quemar los bosques y reemplazarlos con vastas extensiones de tierras agrícolas -el método practicado en la selva tropical en la actualidad-, los indígenas del Amazonas practicaban la horticultura intercalada con árboles frutales y palmeras productoras de frutos y nueces comestibles. La madera era empleada como material de construcción, así como para producir carbón y leña. Y fue el empleo del

18 Antes de Orellana: Actas del 3er Encuentro Internacional de Arqueología Amazónica, Stéphen Rostain (ed.) (Quito, Ecuador: Instituto Francés de Estudios Andinos; Facultad Latinoamericana de Ciencias Sociales; Embajada de Estados Unidos, 2014).

19 William I. Woods, Johannes Lehmann y Bruno Glaser (eds.), Amazonian Dark Earths: Origin Properties Management (New York, EE. UU.: Springer, 2004). 
carbón mezclado con otros detritus, lo que permitió dar una gran fertilidad a los suelos donde prosperaron los huertos cultivados durante muchos siglos.

La práctica de mezclar el carbón con los detritus humanos y de animales, así como todo tipo de desechos, antes de colocarlos en los campos de cultivo, fue lo que gradualmente mejoró la fertilidad de los suelos. Esta práctica permitió un ascenso continuo de la productividad que con el paso del tiempo garantizó la obtención de cada vez mayores cosechas. Las áreas que rodeaban las poblaciones eran empleadas de forma intensiva y se calcula que una hectárea de huertos de selva amazónica podía alimentar entre 15 y 20 personas. Para lograr esta alta productividad por unidad de área cultivada, un complejo sistema de policultivos y un inteligente ciclo permanente de nutrientes aplicados al suelo debía practicarse. Solo cuando los nutrientes, extraídos de la tierra por el cultivo intenso, eran nuevamente reintegrados de forma continua a los suelos, podía lograrse la producción sustentable de largo plazo, obteniéndose así rendimientos agrícolas estables. En el caso de los suelos amazónicos, es crucial que los nutrientes sean añadidos de manera tal que no puedan ser lavados por las lluvias tropicales.

Entonces, mientras el método de slash and burn caracterizado por los fuegos que reducen la biomasa a cenizas, el método slash and char emplea por medio de fuegos cubiertos con tierra y paja, una quema de baja intensidad, que garantiza la exclusión parcial de oxígeno. Mientras el primer sistema empleado en muchas partes del mundo para la preparación de los campos de cultivo, libera gases de invernadero en la atmósfera, el segundo reduce la liberación de estos gases, mediante la retención de grandes cantidades de carbón a lo largo de los siglos, reduciendo así las emisiones de metano y de óxido nitroso desde los suelos. ${ }^{20}$

En síntesis, la economía de las sociedades amazónicas era muy compleja, pues incluía la producción intensiva de alimentos, cosecha de semillas y raíces, tanto en campos de monocultivo como de policultura. También incluía la caza y la pesca intensivas, así como el almacenamiento a largo plazo. Un considerable número de trabajos era llevado a cabo en la edificación de instalaciones permanentes como corrales para tortugas, estanques para piscicultura, así como cultivos permanentes. Se ha determinado la existencia de campos de cultivo en una escala impresionante: alrededor de 50.000 acres en Llanos de Mojos y 15,5 kilómetros cuadrados en Caño Ventosidad en Venezuela, que en teoría podrían haber sustentado a cientos de miles de habitantes.

Los sistemas políticos expandieron sus dominios sobre amplios territorios, algunos de los cuales llegaron a alcanzar extensiones de hasta decenas de miles de kilómetros cuadrados, unificados bajo el poder de jefes supremos. La

20 Michael J. Eden, Warwick Bray, Leonor Herrera y Colin McEwan, "Terra Preta Soils and Their Archaeological Context in the Caquetá Basin of Southeast Colombia”, American Antiquity (EE. UU.) 49, n. 1 (enero, 1984): 125-140 [126], DOI: http://dx.doi.org/10.2307/280517. 
población se hallaba densamente concentrada, con algunos centros que reunían a muchos miles de habitantes. Es así que se han encontrado vestigios de grandes construcciones y podido determinar que algunos de los asentamientos medían muchos kilómetros cuadrados, con una alta densidad poblacional. Prueba de ello son los depósitos de restos culturales y biológicos que alcanzan varios metros de profundidad. Muchos de los restos de estos asentamientos son montículos compuestos de capas de edificaciones derruidas superpuestas entre sí, sobre las que se volvió a construir.

Los asentamientos contaban con varios miles o decenas de miles de habitantes agrupados en grandes entidades políticas y culturales bajo el poder de jefes supremos que proclamaban su origen divino, quienes hacían gala de su estatus al ser cargados en literas profusamente adornadas.

Aunque el número de asentamientos pequeños y simples es mucho más numeroso, los de mayor tamaño muestran una gran complejidad. En ellos se aprecian áreas determinadas para actividades específicas tales como joyería, fabricación de herramientas de piedra, o bien, destinadas a la celebración de ceremonias; sitios usados como cementerios, zonas de aglomeración de unidades domésticas, etc. También construcciones defensivas: empalizadas y fosos.

Las sociedades cacicales se tornaron expansionistas y guerreras con organizaciones sociales jerárquicas, sustentadas en el cobro de tributo y una economía basada en la producción de cosechas y el forrajeo intensivo. Las artesanías alcanzaron un alto desarrollo asociadas a las actividades ceremoniales y al comercio, con una diversidad de objetos cuya estilística representaba figuras humanas, diseños que vinieron a sumarse a los ya existentes de figuras de animales y geométricas. También tuvo lugar la proliferación del culto a ídolos e imágenes asociados a los ancestros de los jefes supremos.

Artículos de cerámica decorada, tejidos, herramientas diversas, alimentos y materias primas eran intercambiados a gran distancia. Para tal propósito existían sitios que funcionaban como mercados en los que cuantiosos intercambios se llevaban a cabo de manera periódica. Cuentas de collares, usualmente de concha, eran utilizadas como medio de pago, en tanto que ornamentos de piedras semipreciosas como las piedras verdes, formaban parte del sistema de intercambio de regalos entre las élites.

Las áreas arqueológicas que se formaron por la acumulación de desechos de los habitantes prehistóricos constituyen una proporción considerable de la superficie terrestre a lo largo de las riberas de los ríos Amazonas y Orinoco. Estos depósitos arqueológicos que datan de los tiempos prehistóricos tardíos son masivos, en ocasiones se extienden de forma por decenas de kilómetros y se encuentran densamente abarrotados de artefactos y restos de plantas carbonizadas, indicación de que allí vivían poblaciones de varios miles de habitantes e 
incluso algunos de hasta decenas de miles, dada su escala y complejidad, por lo que para algunos investigadores estamos en presencia de sociedades con un nivel sociopolítico tal que podrían ser considerados como Estados.

Así, cuando los europeos iniciaron su expansión y navegación por el Amazonas a partir de la década de 1540 , encontraron sociedades con una alta densidad de población, marcadas jerarquías sociales y economías basadas en la pesca, la caza y el cultivo intensivo de maíz y yuca.

La evidencia arqueológica ha venido a corroborar el grado de veracidad de los escritos del siglo XVI: el tamaño y la apariencia de los asentamientos, los productos intercambiados, los depósitos de alimentos, así como la existencia de agricultura y el manejo de los recursos constituyen pruebas irrefutables de que los primeros relatos de europeos sobre estas poblaciones no eran ficción, sino realidad y también que los sistemas de producción de alimentos fueron muy rentables, desmitificando así la supuesta incapacidad de la selva tropical para sustentar gran número de habitantes y sociedades complejas. ${ }^{21}$

\section{Los mayas de las tierras bajas del Petén}

En las primeras dos décadas del siglo XX se debatía ya si los mayas habían empleado algún tipo de agricultura intensiva o si, por el contrario, dependieron para su subsistencia del sistema agrícola de roza y quema. Algunos investigadores plantearon que la población maya tuvo que ser muy elevada, dada la gran cantidad de sitios arqueológicos encontrados, así como el tamaño de las edificaciones en dichos sitios. Tal punto de vista se vio fortalecido al hallarse evidencias de terrazas, así como muros que se suponía reforzaban los campos de cultivo. Con respecto al tamaño de la población, la evidencia era menos contundente. Los cálculos relativos al tamaño de la población carecían de bases sólidas.

A principios del siglo XX los cálculos de la población maya variaban mucho. Quienes argumentaban a favor de una gran cantidad de población también consideraban que los mayas dependían de la agricultura intensiva. Teobert Maler ya en 1911 afirmó que probablemente Tikal era un gran centro urbano con una población de cientos de miles de habitantes, por lo que planteó que las selvas habían sido despejadas en torno a este centro con el fin de desarrollar plantaciones de maíz. En 1929, Thomas Gann adujo que las ciudades de Tikal, Copán y Chichén Itzá probablemente habrían tenido poblaciones que rondaban los 250.000 habitantes. Y, por esos mismos años -1928- Herbert Spinden sugirió que la península de Yucatán, incluyendo el Petén y la actual Belice podrían haber contenido unos ocho millones

21 David Grann, "Under the Jungle”, The New Yorker, 7 de enero de 2010, URL: https://www.newyorker. com/news/news-desk/under-the-jungle. 
La Amazonía y el Petén: ¿dos lugares improbables para el desarrollo de las civilizaciones?

de habitantes durante el período clásico -el de mayor esplendor- con una densidad de unas 31 personas por kilómetro cuadrado. ${ }^{22}$

\section{Mapa 2 \\ Petén y tierras bajas mayas centrales}

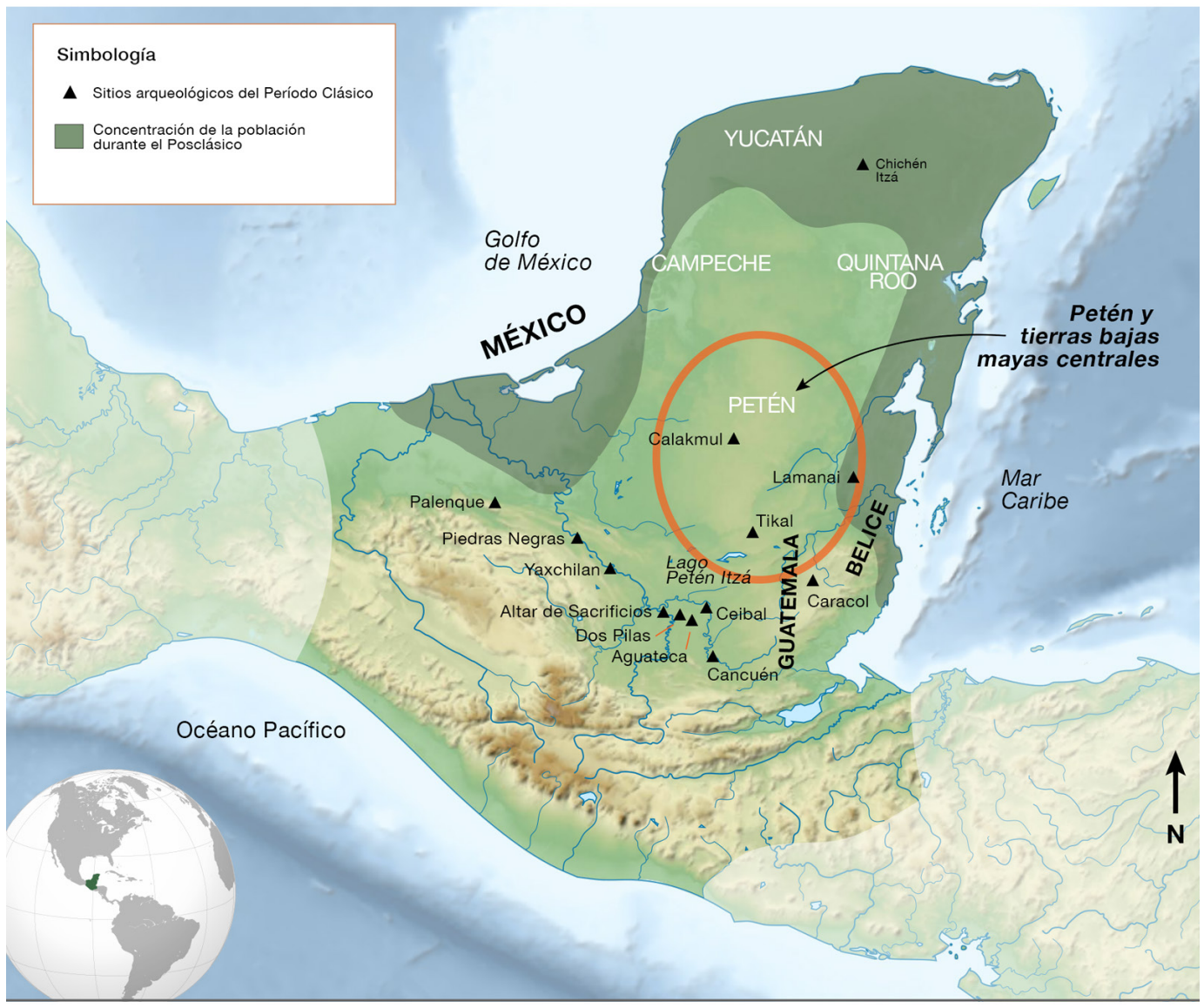

Fuente: elaboración propia a partir de (C) Sémhur/Wikimedia Commons/CC-BYSA-3.0 o Free Art License, URL: https://commons.wikimedia.org/wiki/File:Maya_civilization_location_map-blank.svg.

22 Jeffrey L. Baker, "A history of Research into Maya History", Lost in the Desert (blog), mayo, 2012-diciembre, 2013, URL: https://sierradeagua.wordpress.com/category/maya/. Consúltese: https://sierradeagua.wordpress.com/2013/12/27/a-history-of-research-into-maya-agriculture-part-iv/; este trabajo constituye una valiosa guía para el tema de la agricultura de los mayas.

Revista de Historia N. ${ }^{\circ} 78$

Julio - Diciembre 2018 • pp. 119-147 
Antes de la Segunda Guerra Mundial, solo un estudio detallado de asentamiento se llevó a cabo en el sitio de Uaxactún. Lo realizó Oliver Garrison Ricketson Jr. y su esposa, quienes contaron los montículos de casas en transectos -corte lineal denominado con ese nombre y que cruza una zona determinada- a través de las tierras aledañas al sitio y calcularon el total de la población para esta región. Sin embargo, como lo observó Ricketson, no pudo establecer un lugar para finalizar el corte -transecto-, pues no pudo determinar un límite en el cual terminaban de aparecer completamente los montículos. A partir de este estudio, Ricketson realizó un primer cálculo de 411 personas por kilómetro cuadrado, pero de manera arbitraria lo dividió entre cuatro, llegando así a un cálculo de 102 personas por kilómetro cuadrado. A partir de ambos cálculos, Ricketson afirmó que era imposible que una densidad poblacional como esta pudiese sustentarse con un sistema agrícola de roza y quema. De allí dedujo que los mayas debieron haber dependido de un sistema agrícola intensivo, lo que a su vez habría tenido como consecuencia la erosión del suelo y el subsecuente colapso de la civilización maya y la migración de la población de la zona del Petén hacia el norte.

No todos los investigadores que aceptaron que los mayas tenían una gran población, plantearon que estos dependieran para su subsistencia de un sistema agrícola intensivo. Este fue el caso de Sylvanus Morley, quien en la década de 1920 sostuvo que si bien las tierras bajas mayas constituyeron uno de los territorios más densamente poblados del mundo durante el período clásico -250-900 d.C.-, su sistema agrícola fue el de roza y quema. No obstante, planteó que el tiempo en que las tierras se dejaban en barbecho era inferior a los cinco años. También argumentó que tal reducción del período en que las tierras se dejaban en descanso tuvo como resultado la pérdida de la capa de humus, debido a la erosión causada por las lluvias. Asimismo, argumentó que la pérdida de fertilidad de los suelos fue rápida y como consecuencia se produjo la definitiva crisis agrícola y el colapso de lo que Morley definió como el Viejo Imperio Maya. Así, habría terminado el período clásico en las tierras bajas del Petén, con la consecuente migración de la población sobreviviente hacia el norte de la península de Yucatán.

Morley sustentó su interpretación en las investigaciones que se llevaron a cabo a principios del siglo XX sobre las prácticas agrícolas de los mayas contemporáneos en la península de Yucatán. En estas se determinó que el maíz constituía el $85 \%$ de la dieta alimenticia de los agricultores. Morley consideró que los mayas formaban una sociedad muy conservadora, por lo que sus prácticas agrícolas probablemente eran las mismas que en los tiempos antiguos. Entonces dedujo que, debido a la poca productividad de la agricultura de roza y quema, la población de los mayas durante el período clásico habría sido escasa. También, 
en 1919 O. F. Cook sostuvo que la agricultura de milpa implicaba la destrucción del suelo, y la proliferación de hierbas. ${ }^{23}$

Fue así como la evidencia suministrada por las investigaciones de Ricketson en Uaxactún en la década de 1930, que indicaban una gran población en torno a dicho sitio arqueológico, sobre la idea de que los mayas dependían exclusivamente de la agricultura de roza y quema adquirió cada vez más peso, reforzando la creencia de que nunca hubo una gran población en la región del Petén.

Durante la década de 1940, investigadores como Thomas Gann, quien había sostenido previamente que los mayas habían utilizado agricultura intensiva, revirtió su interpretación, en tanto otros como Cyrus Lundell, también modificó su interpretación original. Este autor había planteado a comienzos de la década de 1930 que los mayas de las tierras bajas disponían de tres diferentes parcelas: la milpa tradicional, otra parcela semipermanente para la siembra de árboles, cercana a la milpa, así como una tercera parcela de producción agrícola permanente junto a sus moradas. Estas últimas constituían huertas cultivadas con plantas perennes, que en la década de 1930 eran sembradas de algodón y tabaco. Como las observaciones de Lundell eran de carácter etnográfico, no fueron aceptadas por los arqueólogos o simplemente sus observaciones con respecto al tema de la agricultura fueron ignoradas. ${ }^{24}$ También fueron rechazadas las observaciones etnográficas que indicaban que los períodos de barbecho se extendían solo de siete a diez años, en tanto que los arqueólogos planteaban que el período de reconstitución del terreno en los mayas del período clásico se prolongaba hasta por veinte años, lo cual más tarde se reveló como un estereotipo, sin sustento en evidencias.

Durante la década de 1930, dos agrónomos, Emerson y Kempton llevaron a cabo una investigación sobre el potencial agrícola del norte de la península de Yucatán. Al entrevistar a los agricultores locales, estos les informaron que los rendimientos del maíz declinaban del primero al segundo año, cuando se sembraba en la misma parcela, lo que ambos investigadores atribuyeron a la invasión de yerbajos. Una observación fundamental de estos investigadores fue su planteamiento de que descubrir el tipo de prácticas agrícolas de los mayas de la antigüedad constituía la llave para la comprensión de la distribución de la población y el tamaño de esta, e igualmente, determinar el sistema económico y social de los mayas, así como las causas del declive del Viejo Imperio. Y si bien Emerson, dos décadas más tarde, señaló que el sistema agrícola de roza y quema constituía el único practicable en Yucatán, aun con la utilización de modernas herramientas y animales de tiro, también afirmó que los nutrientes del suelo se

23 Orator F. Cook, "Milpa Agriculture, A Primitive Tropical System", en: Annual Report of the Smithsonian Institution for 1919 (Washington D.C., EE. UU.: Smithsonian Institution, 1921), 307-326, disponible en URL: http://bulbnrose.x10.mx/Heredity/Cook/CookMilpa.pdf.

24 Cyrus Longworth Lundell, "The Agriculture of the Maya", Southwest Review (EE. UU.) 19, n. 1 (octubre, 1933): 65-77, URL: https://www.jstor.org/stable/43462047. 
perdían debido a esa práctica agrícola. Su idea era que la naturaleza cárstica del suelo de la península de Yucatán impedía la utilización de agricultura intensiva.

A pesar de las diversas investigaciones y desarrollo de planteamientos diversos respecto de las prácticas agrícolas entre los mayas de las tierras bajas en la antigüedad, a partir de fines de la década de 1930 se fue decantando una hipótesis que terminó por imponerse en relación con las características de la agricultura de los mayas: predominó el sistema de roza y quema. Pero al practicarse este de manera intensiva, reduciendo los tiempos del barbecho, de forma inevitable se produjo la degradación ambiental del frágil ecosistema tropical.

Otro modelo sobre las prácticas de subsistencia se propuso en esos mismos años, cuando Lundell llamó la atención con respecto al árbol de ramón -Brosimum alicastrum-, el cual se encontraba comúnmente entre las ruinas mayas. Según Lundell, estos árboles descendían de los aquellos que en la antigüedad habían sembrado los mayas. Al mismo tiempo, observaciones etnográficas realizadas en Honduras Británica -actual Belice- y en Campeche determinaron que, hacia el final de la estación seca, cuando el maíz escaseaba, las nueces del árbol de ramón se mezclaban con el maíz para elaborar las tortillas. Así, se planteó que las nueces del árbol de ramón constituyeron un complemento alimentario de lo obtenido en las milpas. Sin embargo, posteriormente se determinó que las nueces de este árbol solo se emplearon cuando amenazaba la hambruna y que no fue una fuente de subsistencia de importancia entre los mayas de la antigüedad. Fue solo a partir del arribo de los españoles y de la introducción de la ganadería caballar, que estas nueces se explotaron con mayor intensidad como forraje para el ganado.

En la década de 1950, finalmente se impuso un incuestionado modelo de interpretación de la sociedad maya del período clásico, el cual planteaba que la población había sido escasa y que esta dependía para su subsistencia mayormente del sistema agrícola de roza y quema. Este modelo postulaba que los sitios arqueológicos donde se concentraban las grandes edificaciones constituían lugares prácticamente vacíos, habitados exclusivamente por una casta sacerdotal dedicada a cálculos relativos al tiempo y al desplazamiento de los astros en el firmamento. La población rural solo periódicamente acudía, durante las festividades, a los centros ceremoniales. Los productores agrícolas vivían dispersos en pequeñas aldeas en los territorios aledaños, donde sus pobladores cultivaban maíz, frijoles y calabazas y, en menor grado, tubérculos como el camote.

El modelo interpretativo par excellence que se impuso en los años 1950 quedó plasmado en el libro que se convirtió en el magnum opus de los estudios mayas durante esa década, The Ancient Maya de Sylvanus G. Morley, ${ }^{25}$ publicado originalmente en 1946, uno de los más difundidos libros sobre los

25 Sylvanus Morley, The Ancient Maya, segunda edición (California, EE. UU.: Stanford University Press, 1947). 
mayas durante décadas, opinión que fue secundada por otro mayista famoso, J. Eric S. Thompson en su libro publicado en 1954, The Rise and Fall of Maya Civilization. ${ }^{26}$ Es así como en la década de 1950, de manera incuestionable se aceptó que la sociedad maya de la antigüedad se habría caracterizado por su escasa población y esto a su vez como consecuencia de un sistema agrícola de tala y quema de poca productividad.

En esa línea de interpretación, la antropóloga Betty Meggers llegó a plantear, en 1954, la posición más extrema al afirmar que las selvas tropicales al ser muy deficientes en recursos, eran incapaces de permitir el desarrollo de sociedades complejas. Razón por la que aseguró que los mayas del período clásico se asentaron en la región del Petén procedentes de otras partes e igualmente su colapso fue consecuencia de haberse establecido en un territorio inapto para sustentar una población creciente. ${ }^{27}$ Sin embargo, tres años más tarde William Coe cuestionó este planteamiento al sugerir que la agricultura de roza y quema era mucho más productiva de lo que la mayor parte de los investigadores creían. ${ }^{28}$ No obstante, aún en 1962, William T. Sanders sostuvo que la agricultura de roza -desmonte y quema-, utilizada por los mayas, produjo su colapso porque afectó drásticamente su ecosistema. ${ }^{29} \mathrm{Y}$, aunque algunos autores como Dumond y Cowgill (1961) argumentaron que este sistema agrícola era altamente adaptativo y eficiente en determinadas áreas de la selva tropical, no cuestionaron que este fuese el principal sistema de producción agrícola de los mayas. ${ }^{30}$

Pasó más de una década antes de que el modelo de roza y quema, presentado como el sistema agrícola predominante entre los mayas de las tierras bajas durante la antigüedad, fuese cuestionado seriamente. Dos autores, B. L. Turner y N. Hammond, proclamaron en la década de 1980 el fin del modelo de milpa o de roza y quema como el principal sistema de producción agrícola de los mayas. ${ }^{31}$ No obstante, muchas de las suposiciones asociadas con el modelo de la agricultura de roza y quema se mantuvieron. Entre estas, que el suelo y clima

26 Eric S. Thompson, The Rise and Fall of Maya Civilization, segunda edición (Oklahoma, EE. UU.: University of Oklahoma Press, 1973).

27 Betty J. Meggers, "Environmental Limitation on the Development of Culture", American Anthropologist (EE. UU.) 56, n. 5 (octubre, 1954): 801-824, URL: https://www.jstor.org/stable/663814.

28 William Coe, "Environmental Limitation on Maya culture: A Re-Examination", American Anthropologist (EE. UU.) 59, n. 2 (abril, 1957): 328-335, URL: https://www.jstor.org/stable/665231.

29 William T. Sanders y Barbara J. Price, Mesoamerica: The Evolution of a Civilization (New York, EE. UU.: Random House, 1968).

30 D. E. Dumond, "Swidden Agriculture and the Rise of Maya Civilization", Southwestern Journal of Anthropology (EE. UU.) 17, n. 4 (1961): 301-316, URL: https://www.jstor.org/stable/3628942. Ursula M. Cowgill, Soil Fertility and the Ancient Maya (New Haven, EE. UU.: Connecticut Academy of Arts \& Sciences, 1961).

31 Billie Lee Turner II, "The Development and Demise of The Swidden Thesis of Maya Agriculture", en: Pre-Hispanic Maya Agriculture, D. Harrison y Billie Lee Turner II (eds.) (Albuquerque, EE. UU.: University of New Mexico Press, 1978), 13-22; N. Hammond, "The Myth of the Milpa: Agriculture Expansion in the Maya Lowlands", en: Pre-Hispanic Maya Agriculture, D. Harrison y Billie Lee Turner II (eds.) (Albuquerque, EE. UU.: University of New Mexico Press, 1978), 23-34. 
de la selva tropical imponen severas limitaciones al desarrollo de la agricultura, lo cual, según diversos autores es falso, pues existen diferentes investigaciones etnográficas que describen sistemas de producción agrícola intensivos en zonas tropicales de África y de Asia.

William Sanders a fines de la década de 1970 planteó que los mayas recurrieron a la agricultura en los humedales o bajos que se caracterizan por ser pantanosos. Sin embargo, afirmaron que lo hicieron de manera limitada y temporal, en tanto que sus principales cultivos los desarrollaron en las tierras elevadas y secas a lo largo de todo el año. ${ }^{32}$ Por esos mismos años, Robert Netting, quien había realizado trabajos etnográficos entre los Ibo de Nigeria, sugirió que los mayas habían utilizado un sistema agrícola que combinaba lo que llamó un sistema agrícola infield-outfield, en el cual los agricultores cultivaban intensamente parcelas de tierra cerca de su residencia -infield-, en tanto que parcelas adicionales de tierra, ubicadas a cierta distancia de sus casas -outfield-, eran cultivadas mediante el método de roza y quema. ${ }^{33}$

Junto a la aceptación de que el sistema de roza y quema era el predominante entre los mayas de las tierras bajas, también se dio por sentado que estas tierras bajas eran ecológicamente uniformes, pues solo unos pocos investigadores llamaron la atención sobre la variabilidad ecológica existente en las tierras bajas mayas, entre ellos el propio Sanders. Como resultado, a inicios de la década de 1980 se comenzó a consolidar un nuevo modelo explicativo del sistema agrícola de los mayas de las tierras bajas, que planteaba una combinación de agricultura intensiva en humedales con un sistema similar a las conocidas chinampas de los aztecas, complementada con una agricultura de roza y quema en los terrenos elevados y secos.

El empleo de fotografías aéreas dio pie al planteamiento de que los mayas tal como los aztecas dispusieron de un sistema agrícola de "camellones" o campos elevados parecidos a las chinampas del Valle de México. Estos habrían sido levantados en los llamados "bajos" o tierras bajas pantanosas mediante el apilamiento del cieno extraído de los pantanos colocándolo en capas para formar camellones o montones de tierra por encima del agua. Estas chinampas quedaban rodeadas de canales en los que se criaban tortugas y otras especies acuáticas, a la vez que plantas nenúfares se plantaban en el agua para impedir que esta se secara. Se supuso que estos camellones o camas de lodo por encima del agua garantizaban una producción agrícola altamente rentable capaz de suministrar de dos a tres cosechas anuales, aunque requerían del empleo intensivo de trabajo. A la par de esta agricultura intensiva, los cultivadores mayas practicaban la

32 William T. Sanders, "The Jolly Green Giant in Tenth Century Yucatan, or Fact and Fancy in Classic Maya Agriculture", Reviews in Anthropology, 6, n. 4 (1979): 493-506, URL: https://doi.org/10.1080/00988157. 1979.9977472.

33 Chelsea Fisher, "The Role of Infield Agriculture in Maya Cities", Journal of Anthropological Archaeology, 36 (diciembre, 2014): 196-210, DOI: https://doi.org/10.1016/j.jaa.2014.10.001. 
agricultura de roza y quema, que requería dejar la tierra en descanso por períodos de cinco a diez años.

El nuevo modelo explicativo de combinación de ambos sistemas agrícolas empezó a cuestionarse cuando algunos investigadores dudaron de que las fotografías aéreas mostrasen realmente camellones o chinampas. Se sugirió que los patrones en cuadrícula captados en las imágenes fotográficas podrían representar más bien gilgais, que consisten en montículos y depresiones naturales, que se forman en la superficie de suelos arcillosos, dando lugar a elevaciones y hundimientos del terreno que adquieren formas regulares geométricas. Entonces, Michael Coe en 1983 nuevamente planteó que, debido a este malentendido, la agricultura de los mayas del período clásico en realidad dependió al menos en un $75 \%$ de la agricultura de roza y quema, y que esta fue la razón por la que se tornó un problema alimentar a la creciente población durante el período clásico, al tener que extenderse los cultivos hacia zonas de suelos pobres. Así, se habría provocado un descenso de los rendimientos agrícolas, al verse los cultivadores obligados a dejar la tierra en barbecho durante períodos cada vez más cortos, lo que condujo a que la recuperación de los nutrientes del suelo no se produjera. Los esfuerzos realizados por obtener recursos agrícolas en terrenos cada vez más desgastados no dieron resultado: se incrementaron las enfermedades de las plantas y las epidemias de insectos, al tiempo que las hierbas empezaron a invadir los campos de cultivo. Es así como se habría iniciado el colapso de la sociedad al propagarse la malnutrición entre los mayas debido a la creciente escasez de alimentos, lo que redujo la resistencia a las enfermedades, una reducción de la fuerza de trabajo y por tanto menos cultivadores. La combinación de sobrepoblación y de sobreexplotación de los recursos naturales coincidió con un incremento en la construcción de edificios, lo que restó aún más mano de obra a la agricultura y así el colapso se tornó inevitable. Es decir, la explicación del supuesto fin catastrófico de los mayas de las tierras bajas del Petén al final del clásico se sustentó en la idea de que su agricultura dependía mayormente de la agricultura de roza y quema. ${ }^{34}$

Poco después, investigaciones llevadas a cabo en los sitios de Pulltrouser Swamp, Albion Island y Cerros, todos en Belice, demostraron que al menos en estos lugares, los supuestos gilgais no eran tales, sino resultado de la acción de los humanos. Sin embargo, en el caso del sitio de Albion Island, se llegó a la conclusión de que la agricultura de camellones en tierras de humedales estuvo limitada al período preclásico. En el caso de Pulltrouser Swamp, en el norte de Belice, se determinó que estos sistemas agrícolas se habrían construido durante el período preclásico tardío, pero se mantuvieron en uso hasta el clásico tardío. Más recientemente, la aplicación del sistema lidar ha sido revolucionaria para

34 Michael D. Coe, The Maya (New York, EE. U.U.: Thames \& Hudson, 1994), 17-19. 
la comprensión de los paisajes antropogénicos de los mayas de la antigüedad. Esto ha sido evidente en el oeste de Belice, donde la escala y la resolución de estas imágenes han identificado enormes redes de sistemas de terrazas agrícolas, revelando su verdadero alcance y densidad. La combinación de las imágenes lidar con modelos digitales de elevación -DEM-, así como programas de mapas hidrológicos utilizados en la exploración de las cuencas de drenaje asociadas con las terrazas agrícolas en el sitio maya Waybil, en la meseta Vaca Norte en Belice, lograron determinar cómo las terrazas construidas por los mayas crearon pequeñas cuencas de drenaje..$^{35}$

Por otra parte, otros investigadores llamaron la atención para que no se extrapolaran los resultados de las investigaciones del norte de Belice hacia otras partes de las tierras bajas mayas. Así, un pantano localizado al lado del sito de El Mirador en el Petén, se determinó que este perdía su humedad muy rápidamente durante la estación seca como para permitir su empleo para el desarrollo de cultivos. También, Alfred Siemens argumentó que las condiciones de los pantanos o humedales variaban mucho a lo largo de las distintas estaciones y que los mayas de la antigüedad carecían de los recursos técnicos necesarios para hacerle frente a la extrema variabilidad hidrológica de estas zonas pantanosas del Petén, con el fin de explotarles su potencial agrícola. ${ }^{36}$

Al tiempo que se debatía sobre la importancia de los cultivos de chinampas en humedales durante el período clásico maya, Frederick M. Wiseman planteó que los mayas habían expandido un tipo de selva de factura humana o "selva artificial", por medio de la propagación de determinados tipos de árboles que garantizaban que el dosel de follaje de los árboles fuese más abierto, garantizando así que la luz del sol alcanzara las plantas cultivadas a nivel de superficie, como el maíz y los tubérculos. De manera que los mayas habrían dispuesto así de tres distintos tipos de cosechas: maíz y frijoles, tubérculos y árboles como el ya mencionado ramón, cuya nuez se emplearía para la elaboración de harina. A su vez, el dosel del follaje de la selva serviría también para proveer alguna protección de la lluvia, reduciendo así el problema que causa la caída de agua de lluvia sobre el suelo, causante de la lixiviación y erosión de los suelos. ${ }^{37}$

El planteamiento de Wiseman fue corroborado por William J. Folan en una investigación realizada en el sitio de Cobá, en el norte de Quintana Roo, donde mediante el mapeo de la distribución de los árboles económicamente

35 Scott Macrae y Gyles Iannone, "Understanding Ancient Maya Agricultural Terrace Systems through Lidar and Hydrological Mapping", Advances in Archaeological Practice (Inglaterra) 4, n. 3 (enero, 2016): 371 392, DOI: https://doi.org/10.7183/2326-3768.4.3.371.

36 Alfred H. Siemens, "Prehispanic Agriculture Use of the Wetlands of Northern Belice", en: Maya Subsistence: Studies in Memory of Dennis E. Puleston, Kent V. Flannery (ed.) (New York, EE. UU.: Academic Press, 1982), 205-225.

37 Frederick M. Wiseman, "Agriculture and the historical ecology of the Lowland Maya", en: Pre-Hispanic Maya Agriculture, D. Harrison y Billie Lee Turner II (eds.) (Albuquerque, EE. UU.: University of New Mexico Press, 1978), 63-115. 
importantes en dicho sitio, determinó un patrón de distribución concéntrico de los árboles, en el que los árboles frutales iban decreciendo según la distancia del centro del sitio. Tal patrón fue interpretado como evidencia de que los mayas que vivían cerca del centro de Cobá hacían crecer los árboles en sus huertos caseros, en tanto que la agricultura de roza y quema era practicada más lejos en la periferia del sitio. ${ }^{38}$ También Gómez-Pompa, en estudios realizados en otras partes de la península de Yucatán, planteó que las especies de árboles económicamente importantes que crecían en torno a los restos de los muros de edificaciones prehispánicas, constituían los remanentes de selvas antropogénicas. ${ }^{39}$

A pesar de estos nuevos planteamientos, Turner y Miksicek alegaron que el patrón de distribución de los árboles en Cobá no estaba reservado a los árboles nativos, sino que se repetía con los árboles de cítricos que habían sido introducidos por los españoles. Así, concluyeron que las selvas de Cobá no eran reminiscencias de la selva prehispánica, sino más bien resultado de más recientes prácticas de siembras arboríferas a partir del arribo de los españoles. También, argumentaron que sus investigaciones, que incluyeron los análisis de polen fósil, semillas, tallos y fragmentos de madera, les permitieron llegar a la conclusión de que el maíz fue el principal producto alimenticio de los mayas de las tierras bajas, pero que también cultivaban la calabaza, el agave, el algodón, así como diversas especies de árboles. Sin embargo, ni las nueces del árbol de ramón, ni el cacao, ni los tubérculos ni el amaranto constituían productos de importancia. En realidad, las nueces del árbol de ramón solo se empleaban en momentos de escasez, a las que se recurría en momentos de hambrunas. ${ }^{40}$ Otros investigadores como Lambert y Arnason concluyeron que la distribución de los árboles, en particular el de ramón, obedeció a factores de orden ecológico, más que a razones económicas de la sociedad del período prehispánico. Su alta densidad entre las ruinas de las partes centrales de los centros ceremoniales fue el probable resultado de sus necesidades para crecer y reproducirse, pues las ruinas les proporcionaban un ambiente óptimo para su proliferación. Por tanto, estaban allí no porque fuesen descendientes de árboles sembrados por la aristocracia maya, como lo habían pensado otros investigadores. ${ }^{41}$

38 William J. Folan, "Coba Archaeological Mapping Project, interim report № 2 y 3. Cobá-Quintana Roo, Mexico August 6, 1975", Boletín de la Escuela de Ciencias Antropológicas de la Universidad de Yucatán (México) 22-23 (enero-abril, 1977): 52-71.

39 Arturo Gómez-Pompa y Aandrea Kaus, "Taming the Wilderness Myth: Environmental Policy and Education are Currently Based on Western Beliefs about Nature Rather than on Reality", BioScience, 42, n. 4 (abril, 1992): 271-279, DOI: https://doi.org/10.2307/1311675.

40 B. L. Turner y Charles H. Miksicek, "Economic Plant Species Associated with Prehistoric Agriculture in the Maya Lowlands", Economic Botany (EE. UU.) 38, n. 2 (abril, 1984): 179-193, DOI: https://doi. org/10.1007/BF02858831.

41 J. D. Lambert y J. T. Arnason, "Ramon and Maya Ruins: An Ecological, Not an Economic, Relation", Science (EE. UU.) 16, 216, n. 4543 (abril, 1982): 298-9, DOI: https://doi.org/10.1126/science.216.4543.298. 
Al comenzar la década de 1990 empezó a quedar clara, la diversidad de las prácticas agrícolas utilizadas por las mayas de la antigüedad. Así, por ejemplo, en las colinas Puuc del noreste de la península de Yucatán, Nicholas Dunning identificó áreas que contenían suelos con altos niveles de fósforo. Según su interpretación, esto constituía prueba de que las parcelas de tierra que empleaban los agricultores mayas habían sido fertilizadas. Puesto que tales parcelas colindaban con las casas, consideró que se trataba de huertos caseros. Al comenzar la segunda mitad de dicha década, Dunning encontró en la región de Petexbatún, en el sudeste del Petén, amplia evidencia de la existencia de terrazas en el sitio arqueológico de Seibal. Planteó que el terraceo para agricultura empezó en el período clásico temprano -250-600 d.C.- expandiéndose su uso a través de las tierras bajas durante la gran expansión de la población que alcanzó sus máximas cotas en el período clásico tardío/terminal -600-900 d.C.-. Posteriormente, los mayas abandonaron el sistema de terrazas en la agricultura. ${ }^{42}$

Durante esos mismos años, Patrick Culbert encontró los restos de un sistema de canal prehispánico en unos humedales pantanosos cerca del sitio de El Pedernal. Como resultado de este conjunto de investigaciones y descubrimientos se reforzó la idea de que existía una gran diversidad de prácticas agrícolas en las tierras bajas de los mayas de la antigüedad. ${ }^{43}$

Investigaciones posteriores concluyeron que los pantanos que se forman en los suelos karst en lugares adyacentes a muchos sitios arqueológicos mayas, llamados bajos, fueron fundamentales para el cultivo de maíz en el largo plazo y constituyeron un factor clave para el florecimiento de la civilización maya ${ }^{44}$ Otras investigaciones determinaron que los mayas recurrieron a la fertilización de algunos suelos. Encontraron que estos suelos cenagosos contenían perifiton -detritus de algas y minerales que se acumulan en las aguas poco profundasdato que fue interpretado como que los mayas empleaban estos detritus como fertilizantes, lo que ha sido corroborado por investigaciones etnográficas, en las que se concluyó que los agricultores mayas contemporáneos emplean materia orgánica obtenida de las tierras cenagosas. ${ }^{45}$ Estudios detallados en las zonas pantanosas del norte y noroccidente de Belice proveyeron clara evidencia de que sistemas de campos elevados o camellones fueron utilizados en el período

42 Nicholas P. Dunning, Timothy Beach y David Rue, "The Paleoecology and Ancient Settlement of the Petexbatun Region, Guatemala", Ancient Mesoamerica (Inglaterra) 8, n. 2 (1997 [en línea: octubre, 2008]): 255-256, DOI: https://doi.org/10.1017/S0956536100001711.

43 Nicholas P. Dunning, Sheryl Luzzadder-Beach, Timothy Beach, John G. Jones, Vernon Scarborough y T. Patrick Culbert, "Arising from the Bajos: The Evolution of a Neotropical Landscape and the Rise of Maya Civilization", Annals of the Association of American Geographers, 92, n. 2 (2002): 267-283, DOI: https:// doi.org/10.1111/1467-8306.00290.

44 Adam Calvin Parker, "Evidence of Ancient Maya Agriculture in the Bajos Surrounding Tikal, Guatemala", All Thesis and Dissertations (EE. UU.) 5784 (2015), URL: https://scholarsarchive.byu.edu/etd/5784.

45 Scott R. Hutson, Ancient Maya Commerce: Multidisciplinary Research at Chunchucmil (Boulder, EE. UU.: University Press of Colorado, 2017), 202. 
clásico tardío. ${ }^{46} \mathrm{E}$ igualmente, otras investigaciones llevadas a cabo en Belice también determinaron el empleo de otros sistemas de producción agrícola tales como las terrazas en laderas de colinas. ${ }^{47}$ Por otra parte, en la región de Yalahau, en el noreste de Yucatán, que fue muy poblada con aldeas y centros ceremoniales durante los períodos preclásico tardío y clásico temprano -aproximadamente desde el 100 a.C. hasta el 450 d.C.-, se encontró evidencia de cultivos en humedales no permanentes a lo largo de todo el año. A diferencia del sistema de camellones empleado en las tierras pantanosas de Belice, en esta parte de Yucatán, se recurrió al alineamiento de rocas con el fin de controlar el movimiento del agua, así como a la colocación de cieno con contenido de algas para enriquecer las parcelas de cultivos. También se determinó que los aldeanos sembraban árboles en sus comunidades. ${ }^{48}$

En la actualidad se plantea que existió una amplia variedad de prácticas agrícolas empleadas por los mayas de las tierras bajas durante la antigüedad, cada una de ellas adaptadas a las condiciones ecológicas locales. Por tanto, a diferencia de lo que ocurría en los años anteriores y posteriores a la Segunda Guerra Mundial, cuando se afirmaba que los mayas dependían para su subsistencia de la agricultura de roza y quema, único sistema viable en las condiciones ecológicas de la selva tropical, hoy no se plantea la existencia de un único modelo empleado en los períodos preclásico y clásico para su subsistencia.

Hay quienes plantean que coexistieron dos sistemas agrícolas: mientras en las áreas con tierras cenagosas de los bajos se practicó una agricultura permanente del maíz, en las áreas más elevadas habría predominado la selva junto con actividades de silvicultura, así como el cultivo de plantas en huertos caseros, en parcelas aledañas a las casas.

Sin embargo, se determinó que tampoco este planteamiento de un sistema dual era correcto, dado que la calidad y cantidad de tierras susceptibles para el desarrollo de la agricultura en los alrededores de las ciudades mayas variaban de acuerdo con su localización. Así, en las tierras bajas del Petén y en la región Puuc, en el noroeste de la península de Yucatán, el suelo era relativamente fértil, pero restringido a determinadas pequeñas porciones de terreno. En otras partes, se recurrió al uso de camellones o campos elevados -semejantes a las chinampas

46 John S. Jacob, "Ancient Maya Wetland Agricultural Fields in Cobweb Swamp, Belize: Construction, Chronology, and Function", Journal of Field Archaeology, 22, n. 2 (1995 [en línea: julio, 2013]): 175-190, DOI: http://dx.doi.org/10.1179/009346995791547877.

47 Paul F. Healy, John D. H. Lambert, J. T. Arnason y Richard J. Hebda, "Caracol, Belize: Evidence of Ancient Maya Agricultural Terraces", Journal of Field Archaeology, 10, n. 4 (1983 [en línea: julio, 2013]): 397-410, DOI: https://doi.org/10.1179/009346983791504200. Julie L. Kunen, "Ancient Maya Agricultural Installations and the Development of Intensive Agriculture in NW Belize", Journal of Field Archaeology, 28, n. 3-4 (2001 [en línea: julio, 2013]): 325-346, DOI: https://doi.org/10.1179/jfa.2001.28.3-4.325.

48 Scott L. Fedick y Bethany A. Morrison, "Ancient use and manipulation of landscape in the Yalahau region of the northern Maya lowlands", Agriculture and Human Values, 21, n. 2-3 (junio, 2004): 207-219, DOI: https://doi.org/10.1023/B:AHUM.0000029401.39131.ad. 
aztecas- cerca de los cursos de agua y las planicies inundables. En algunas de estas localidades se construyeron terrazas de piedra con la finalidad de recolectar los fértiles depósitos de limo.

En el norte de la península de Yucatán, donde la estación seca era más prolongada, también se empleaba el agua de los cenotes -derivado del nombre original en maya $t z$ 'onot-, hoyos en la superficie del terreno calizo que daban acceso a las cavernas subterráneas por donde circulaba el agua en ríos sumergidos. También se empleaban cisternas excavadas en la piedra caliza, que tenían forma de botellas llamadas chultunes -chultunob en maya-, las cuales eran impermeabilizadas internamente por medio de $\operatorname{arcilla}^{49}$.

En el área central y la zona sur de las tierras bajas mayas, donde la selva era abundante, esta era clareada y el terreno despejado empleado para cultivos. Sin embargo, la tierra declinaba en su fertilidad con relativa rapidez al sometérsela al sistema de cultivo de roza y quema. Aún así, con el fin de maximizar la productividad, los cultivos combinaban frijoles y calabazas al lado del maíz, con el fin de que las matas de frijol pudiesen ascender por los tallos de las plantas de maíz y las plantas de calabazas impidieran la erosión de los suelos.

Pero el cultivo de maíz-frijoles-calabazas, se alternaba con rodales de árboles frutales, el cultivo de tubérculos y otras cosechas, a la vez que amplias zonas se dejaban sin explotar para que allí prosperara la selva naturalmente -guamil-. Estos terrenos se empleaban entonces para cazar las diversas especies de animales que poblaban, recolectar plantas y nueces silvestres, a la vez que servían como fuente de aprovisionamiento de madera.

También se utilizaron pequeñas parcelas para el cultivo de huertos en los alrededores de las casas de habitación. Investigaciones recientes han evidenciado la importancia de estos huertos cuyas tierras eran fertilizadas con estiércol humano y barro recogido en los terrenos pantanosos cercanos. Se considera que eran altamente productivos y que tuvieron un impacto en la dieta por su capacidad de sustentar mucha gente, a la vez que permitieron un uso más pausado de la agricultura de roza y quema por no tener tanta dependencia de este sistema agrícola. ${ }^{50}$

Hubo ciudades que prosperaron en lugares que no disponían de tierras para la agricultura, pero podían comerciar con ciudades más productivas. Intercambiaban, por ejemplo, esclavos, sal, miel de abeja y otros bienes preciosos, tales como metales, plumas y conchas, que canjeaban por productos alimenticios.

Se desconoce aún cómo las parcelas de tierra de mayor tamaño eran distribuidas y la forma en que las tierras agrícolas pasaban de una generación a otra, así como el nivel de la participación estatal en la administración de la producción

49 Arthur Demarest, Ancient Maya: The Rise and Fall of a Rainforest Civilization (Cambridge, Inglaterra: Cambridge University Press, 2004), 141.

50 Ibid, 132. 
agrícola. Se sabe que muchos hogares, en forma privada, cultivaban pequeños huertos, en especial de vegetales y frutas. Una vez cosechados, los productos alimenticios eran almacenados en hórreos de madera sobre el suelo, o bien, en subterráneos chultunes.

\section{Conclusiones}

Lo que en la actualidad sabemos de la Amazonía de hace mil años, sugiere un mundo no solamente muy diferente a como es hoy, sino también a como se le pensó durante largos años. Existía una selva, pero que a trechos estuvo ocupada por claros de bosque donde prosperó la agricultura, grandes aldeas e incluso ciudades, vinculadas entre sí por medio de anchos y largos caminos. También, todo un conjunto de diques, presas y canales se encontraban distribuidos por millares de kilómetros cuadrados. En algunas localidades se encontraban centros ceremoniales delimitados por alineamientos de piedras colocados en forma de círculos. Sobre montículos elevados se erigían las moradas de los jefes y los lugares para el desarrollo de rituales.

Entonces, la imagen que todavía prevalece en el imaginario popular de que la Amazonía fue siempre una selva indómita, un paraíso prístino, donde la huella del hombre apenas si dejó traza, pues sus pobladores escasos vivían de la recolección y la caza o a lo más de la agricultura de roza y quema, desplazándose constantemente en medio de la inmensidad verde, ha sido desmentida por medio de las investigaciones arqueológicas realizadas en las últimas tres décadas. Se determinó que, por el contrario, fue un territorio ocupado por centenares de sociedades indígenas de muy diverso tipo: algunas muy jerarquizadas, lideradas por jefes supremos que gobernaban sobre miles de agricultores, también capaces de organizar grandes ejércitos con miles de guerreros, que ocupaban asentamientos de hasta 19 hectáreas de extensión, las cuales se supone alcanzaron su máximo desarrollo entre el 1250 y el 1500 d.C.

Se considera que los trabajos tales como montículos, caminos, empalizadas, etc., se encuentran distribuidos en más de 400.000 kilómetros cuadrados en más de 1.300 sitios, de los cuales más del $60 \%$ deben aún ser localizados y explorados. ${ }^{51}$ La base sobre la que se sustentaban estas sociedades, la constituían sistemas de producción de alimentos de alto rendimiento, desmitificando así la supuesta incapacidad de la selva tropical para mantener gran número de habitantes y sociedades complejas.

51 Jonas Gregorio De Souza, New light Under the Amazon Rainforest: Uncovering Archaeological Landscapes and Cultural Forests along the Southern Rim of the Amazon Using UAV-Lidar (Investigación en curso, Centre for the Archaeology of the Americas, University of Exeter, Inglaterra). 
En las tierras bajas de los mayas, desde antes de la Segunda Guerra Mundial, se impuso el planteamiento de que los agricultores subsistían sobre todo del empleo de un sistema agrícola de roza y quema e igual a como Meggers originalmente planteara para la Amazonía; se sostuvo que en la selva mesoamericana, también, debido a la fragilidad de los suelos, éstos quedaban agotados rápidamente, por lo que los agricultores estaban condenados a abrir en forma continua nuevos claros en la selva, dejando en abandono las tierras dedicadas al cultivo después de pocos años, con el fin de que se reconstituyera allí nuevamente la selva y los suelos recuperasen su fertilidad. En consecuencia, se afirmó que la población debía vivir de manera muy dispersa y que nunca se alcanzó una alta densidad poblacional comparable a la de las regiones de los altiplanos del Valle Central de México y de Oaxaca, donde sistemas de cultivo intensivos permitieron el desarrollo de una gran concentración de población.

La visión de un modelo caracterizado por la existencia de centros ceremoniales casi vacíos, con muy pocos habitantes ocupándolos de manera permanente, en tanto dispersas en sus alrededores se encontraban pequeñas comunidades aldeanas de agricultores quienes ocasionalmente convergían en ellos. Solo a partir del Proyecto Tikal, realizado en la década de 1950 por la Universidad de Pennsylvania, comenzó a modificarse esta interpretación de los mayas de la antigüedad. ${ }^{52}$ Como resultado de estas investigaciones quedó demostrado que los centros ceremoniales mayas eran en realidad ciudades: se encontraban habitados por un gran número de individuos pertenecientes a la élite, oficiales del Estado, sacerdotes, artesanos y en sus respectivos hinterlands se agrupaban densas poblaciones de agricultores. Constituían sociedades complejas, estratificadas y con grupos de individuos especializados en distintos oficios.

Los diversos estudios de patrones de asentamiento realizados en las décadas posteriores permitieron entender cómo en las selvas del Petén prosperaron múltiples ciudades densamente pobladas. Que todo el territorio que abarca la península de Yucatán, el Petén y los actuales Belice y noreste de Honduras estuvo poblado por unos 15 millones de habitantes. Para ello, los mayas de la antigüedad desarrollaron una variada agricultura y silvicultura adaptada a las muy diversas variedades microambientales de todo este extenso territorio.

La diversidad de las técnicas de producción empleadas tanto por los antiguos habitantes de la Amazonía como del Petén copiaba la estructura de la selva permitiendo a los sistemas de cultivo adaptarse a los patrones de drenaje, el tipo de suelo y su profundidad, su declive, la caída de la lluvia y otras características microambientales. Los problemas de agotamiento, erosión, lixiviación del suelo y su laterización eran evitados gracias a la aplicación de muy diversas técnicas de cultivo, cada una adaptada a las peculiares condiciones locales.

52 Francisco Estrada-Belli, The First Maya Civilization: Ritual and Power Before the Classic Period (New York, EE. UU.: Routledge, 2011), 7. 
Nunca existió en dichas regiones el monocultivo, sino que junto a una agricultura de semillas, también tuvo gran importancia el cultivo de tubérculos, a la vez que los árboles frutales proveían recursos y los terrenos que se conservaban como selva se empleaban para la caza y la recolección. También se empleaba el estiércol humano como fertilizante en los humedales de las tierras bajas de los mayas y la terra preta en las tierras amazónicas.

En cuanto a la práctica de la agricultura de roza y quema, la erosión era mucho menor a lo que previamente se pensaba, puesto que los terrenos clareados eran pocos, ya que los agricultores complementaban la dieta de lo que allí cultivaban con lo obtenido de los árboles frutales, la caza y la recolección en los extensos terrenos no clareados.

En suma, los sistemas de producción y obtención de alimentos de los indígenas de ambas regiones antes del arribo de los europeos estaban bien adaptados tanto a las condiciones del ambiente local como a las respectivas densidades de población. Estas últimas constituían el determinante de la extensión de los sistemas de agricultura intensiva. Así, en la mayor parte de las zonas, la diversidad en las prácticas de subsistencia, la dispersión de los sistemas de cultivo -intercalados con porciones de selva-, como la toma en cuenta de las variaciones microambientales fueron los factores que condujeron al éxito de estos agricultores en las selvas tropicales. 
